\title{
Sonhos: territórios compartilhados 144
}

\author{
Carmen C. Mion ${ }^{145}$ \\ "Dentro de nós há uma coisa que não tem nome, essa coisa é o que somos." \\ Ensaio sobre a Cegueira \\ José Saramago
}

Como vocês puderam apreciar através dos trabalhos apresentados ao longo dos dois eixos da Bienal, são inúmeras as fronteiras externas e internas, culturais, políticas, sociais, raciais e outras com que nos deparamos, sendo que, frequentemente, encontramos resistências de toda sorte aos movimentos que buscam atravessá-las ou mesmo atenuá-las. Em nosso encontro hoje, sobre sonhos e seus territórios compartilhados, me limitarei a uma breve reflexão sobre as nossas fronteiras internas, as inúmeras cesuras psíquicas com as quais nos deparamos cotidianamente e as vias ou movimentos que buscamos em nossa prática para que possamos, senão atravessá-las, vislumbrar o outro lado através desses espelhos transparentes (Bion, 1992).

Ao abordar o sonho como a via régia para o Inconsciente, essa primeira fronteira no interior da própria pessoa a ser estudada, já que jamais abordada antes pela ciência, Freud inaugurou um campo de conhecimento que tem o sonho como paradigma. O campo em que a prática clínica psicanalítica se estabeleceu foi o território do reprimido, aquele com o qual nós analistas estamos familiarizados; conhecemos seus caminhos e passagens pelas quais nos movemos com nossos pacientes "neuróticos". Aqui, as turbulências emocionais e somáticas que o psicanalista e o paciente experimentam no consultório podem ser sonhadas com elementos da vida psíquica do paciente e do próprio psicanalista através das associações livres e atenção flutuante. Ou seja, há uma transformação das impressões sensoriais internas e externas em elementos-alfa que acabarão por constituir os pensamentos oníricos de vigília e os sonhos (Bion, 1962). Mas o que acontece aos pacientes e à função psicanalítica quando as fronteiras entre as

\footnotetext{
144 Trabalho apresentado na mesa "Sonhos: território compartilhado" no II Simpósio Bienal SBPSP "Fronteiras da Psicanálise: a clínica em movimento" no dia 29 de agosto de 2020.

145 Analista didata da SBPSP, docente e supervisora do Instituto de Psicanálise Durval Marcondes, pósgraduação pelo Mental Health Clinical Research Center, Iowa.
} 
diferentes dimensões psíquicas e suas interfaces estão fechadas ou são inexistentes?

Os sonhos, sabemos, são algumas das criações humanas mais magníficas, enigmáticas, desconhecidas e criativas (Grotstein, 2000). Somos mais nós mesmos sonhando os sonhos que nos sonham. Às vezes, a imaginação e as imagens oníricas estão relacionadas a tentativas de alcançar significados, como uma mitologia privada, não necessariamente ao desejo. Através dos sonhos e do sonhar nos aproximamos de nós mesmos, atravessamos fronteiras intrapsíquicas e intersubjetivas - lembrando que sonhar não basta, pois é necessário "sonhar" nossos sonhos, o que implica movimentos entre diferentes dimensões psíquicas. Guiados por entre passagens ocultas em nossos sonhos, podemos atravessar as cesuras entre as seguintes dimensões: Psicossomático $\leftrightarrow$ Somatopsíquico, Interno $\leftrightarrow$ Externo, PS $\leftrightarrow \mathrm{D}$, Consciente $\leftrightarrow$ Inconsciente, Finito $\leftrightarrow$ Infinito, Passado $\leftrightarrow$ Presente $\leftrightarrow$ Futuro. No entanto, as defesas alinhadas contra agonias e terrores impensáveis roubam do indivíduo a possibilidade de trabalho-sonho- $\alpha$ e pensamentos oníricos de vigília, eliminando, consequentemente, a précondição para o sonhar, o impulso criativo e a vida (Mion).

Para nós, psicanalistas, atualmente essas questões de um espaço e tempo ou não-espaço e não-tempo são matérias do dia a dia de nossos consultórios. Como indica Bion (1977/1989), para o analista essas questões são práticas, não teóricas. O trauma aparece aqui como terrores e agonias que não podem adquirir sentido e que excedem em intensidade a capacidade de serem experenciados, vividos psiquicamente, pelo sujeito. Em outras palavras, tudo que não pode acontecer no contexto de uma relação humana e ser experenciado como sonhos compartilhados e/ou realidade compartilhada tende a ser colocado no campo do não humano, torna-se impensável e desperta terrores e agonias sem nome e impensáveis. Nos últimos anos, cada vez mais analistas consideram que além da análise das partes neuróticas da mente, existe também a necessidade de trabalhar de modo a criar ou reforçar estruturas psíquicas fracas, ineficientes ou inexistentes, que impossibilitam ao paciente sonhar por falta de um "espaço" psíquico para o onírico. Atualmente, temos disponível uma ampla bibliografia relacionada ao nível de funcionamento psíquico mais intimamente associado com o não-representado, experiências pré-verbais da mente primordial e/ou traumas 
precoces, de estados de profundo desamparo psíquico e/ou de desintegração/não integração.

Como o tempo é curto, apenas citarei alguns fenômenos e correspondentes conceitos que fazem parte da clínica contemporânea e que estariam incluídos no não-representado, agora com uma ampliação conceitual: a pulsão de morte e a compulsão à repetição de Freud; os elementos-beta e a parte psicótica e nãopsicótica da personalidade, o uso da contratransferência, da intuição do analista e transformações em "O" de Bion; a descatexia com o conceito da "mãe morta", alucinação negativa, fenômenos proto-psíquicos de Green; o gesto que cai no vazio, a regressão fusional e dependência absoluta do objeto, o objeto-subjetivo, objeto transicional de Winnicott; o objeto transformacional de Bollas; teoria do campo como um terceiro e o trabalho de narrativa construída pela dupla, de Ferro; a necessidade de figurabilidade apontada pelo casal Botella; a abordagem das patologias psicossomáticas como restrições dos conflitos à esfera somática, completamente desprovidos de simbolização, às vezes com riscos de morte, propostos pelos franceses Marty e De M’Uzan e outros.

Green (2005) aponta os seguintes fatores que acredita serem comuns a todos esses estados, independente da filiação teórica dos autores: a confusão entre sujeito e objeto; o fato de que a capacidade de simbolizar depende do objeto; a necessidade para integração estrutural através do objeto. Os sintomas aparecem contidos em quatro grupos: 1. exclusão somática, como nas doenças psicossomáticas; 2. expulsão via ação, como nas atuações em geral cuja razão o paciente desconhece (vistas agora como comunicações), atuações masoquistas, adições, todas para aliviar a dor psíquica; 3. cisões com identificações projetivas violentas aliadas a uma resultante área de solidão, localizada em camadas mais profundas do self; 4.descatexia, desinvestimento ou desligamento afetivo do objeto, (o que Bion denomina ataques aos vínculos, resultando em uma depressão primária, por uma consciência moral primitiva), onde um objeto necessitado, porem não representado, pode tornar-se um perseguidor interno eternamente presente e um objeto idealizado onipotente e crítico, resultando em impossibilidade de pensamento (existem apenas pensamentos psicóticos); a depressão vazia (Green), onde o paciente tenta se ater a um certo estado de vazio aspirando ao nada ao não-sendo, para fugir à intrusão ou à separação do objeto, persecutório ou idealizado. Nessa situação, por um lado o objeto mau está sempre 
invadindo, por outro, o bom objeto é inacessível e como ambos são parte do mesmo objeto, torna-se impossível constituir a ausência. Nesse grupo, Green (1975) refere-se também às observações de Winnicott, (1971) quando esse descreve quebras ou fraturas na continuidade da existência da criança, que se seguem a determinadas falhas do objeto (ausência muito prolongada, depressões, psicoses, ausência de rêverie materna) ou por impossibilidade da própria criança levando aos vazios ou buracos psíquicos ausentes de sentidos ou significados por desinvestimento do objeto, configurando-se a falha de representação psíquica dos objetos e de si mesmo.

Parto, com Bion, da premissa de que Eros é inconcebível sem o objeto e, sendo o papel do objeto primário decisivo, não há experiência emocional desvinculada de uma relação. Os encontros entre analista e analisando na sessão analítica são impregnados pela emoção. Quando despojada de emoção, a relação aproxima-se do inanimado, diminui a sua vitalidade, e nos deparamos com o negativo dos vínculos. O encontro, despojado dos conteúdos emocionais vivos, torna-se "tecnológico" e causa-nos profunda estranheza no contato com o paciente. A partir do modelo da rêverie (devaneio) materna em relação às identificações projetivas do seu bebe, através da sua continência, função-alfa e capacidade de transformar e nomear os terrores vividos, será construída a capacidade de representar psiquicamente. A criança irá progressivamente tornando-se capaz de representar o objeto na sua ausência, constituindo-se um "objeto interno", que lhe permitirá tolerar a ausência do objeto. Na realidade, vai se criando um espaço psíquico para o sonhar, no dizer de Bion, introjeção do

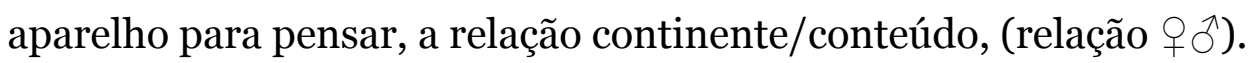

Seja por falha do objeto, excessivamente traumático ou não suficientemente bom, seja por incapacidade de tolerar a frustração, voracidade e destrutividade do bebe (lembrando que trata-se sempre de uma interação entre ambos), a capacidade de manter o objeto internamente será destruída, interrompida ou nem chegará a se desenvolver, (um desastre que envolve a própria preconcepção). Nessas situações ocorre uma falha do vínculo entre a pulsão e o conteúdo inconscientes, formando "vazios" na estrutura psíquica. Estamos aqui na área da mente primordial segundo Bion, ou dos fenômenos proto-psíquicos segundo Green. 
Com essa afirmativa de que para nascer um psiquismo é necessário outro psiquismo, capaz de pensamento onírico, Bion abriu o campo do intersubjetivo na relação analítica, dos "territórios" oníricos compartilhados e flutuações nas fronteiras eu/outro. Do ponto de vista da técnica, colocou a pessoa do analista na sala de análise, no sentido em que ele propõe o uso da sua visão binocular (consciente/inconsciente). Com isso, a presença da subjetividade do analista adquire importância na relação analítica, possibilitando-lhe uma observação fina, a utilização de sua intuição analiticamente treinada e informada, a captação do fato selecionado no campo criado pela dupla. $\mathrm{O}$ analista acolhe os sonhos do seu paciente, nele depositados, e que o fazem experimentar emoções, pensamentos, afetos que tornam possível ao analista metabolizar e comunicar o que o paciente não pode conter ou elaborar. A sessão passa a ser uma sucessão de movimentos resultantes da interação das duas mentes, desde o início do encontro.

O foco do analista é o material para o qual ele tem evidência direta, isto é, a experiência emocional da dupla analítica no momento da sessão (“O”); e a tarefa analítica consistirá em "sonhar" o encontro da dupla, analista e paciente, através da capacidade do analista para rêverie (devaneio e uso da imaginação), uso de conjecturas imaginativas, contratransferências e intuição no campo intersubjetivo, além de acolher e pensar os seus próprios pensamentos oníricos de vigília. Com sorte, o analista será capaz de conter, sonhar e discernir a qualidade psíquica que o paciente não é capaz de perceber e que provoca seu sofrimento, ou seja, a qualidade psíquica do conteúdo emocional vivido como um perseguidor e que precisa ser eliminado ("quero me livrar desse sentimento"). Ao invés de focar principalmente nas ansiedades, defesas, cisões, retorno do reprimido ou fantasias inconscientes, embora eventualmente elas se revelem na interação da dupla, o analista se volta para a possibilidade de fortalecimento ou mesmo desenvolvimento de capacidades e estruturas psíquicas do analisando, a partir de uma relação viva. Ambos se nutrem da experiência, em direção à expansão psíquica da dupla. O desenrolar desse processo vai depender das qualidades psíquicas do analista que serão comunicadas ao paciente através dos canais de comunicação afetivos, e dos seus inevitáveis impactos sobre a mente do paciente. Com isso, na cena analítica, o não saber, no aqui e agora da relação vem para o primeiro plano, favorecendo um vínculo de intimidade e criatividade ao longo do tempo. 
Gostaria de lembrar aqui, como ressaltam Levine\&Reed, que as palavras são no início percepções sensoriais auditivas que têm acesso direto à consciência, opondo-se à sua função semântica, e assim também implicam numa relação com o objeto pois torna-se uma memória (notação) de um som feito por outro, pelo objeto. As palavras então teriam que ser apresentadas inicialmente ao aparelho sensorial. O casal Botella traduz Darstellung (apresentação do objeto) por figurabilidade que se apresenta ao analista formando uma imagem que estruture e transmita algo implícito ou iminente, mas ainda sem representação na psique do paciente ou do analista. Nesse campo, Roosevelt descreveu como o desenrolar de um impasse analítico pode resultar em um enactement inconsciente como uma co-criação de algo nascente que dê forma a algo nascente ainda sem representação ou incipiente. Só depois da figuração ter acontecido é que poderá haver algo a ser reprimido e posteriormente desvelado. Enfim, uma mudança de foco para o fortalecimento, criação e desenvolvimento de capacidades psíquicas. Situações em que me parece que a necessidade de converter a experiência emocional em sonhos torna-se mais importante do que converter sonhos em experiência consciente racional, como propôs Freud.

Como salientei em trabalho anterior paradoxalmente, esse colapso que ocorreu no passado ainda "não aconteceu para o paciente", porque não pôde ser "experenciado" pelo sujeito. Assim, podemos ver o paradoxo de uma organização defensiva desenvolvida inconscientemente pelo paciente para evitar uma temida catástrofe futura, que na realidade já aconteceu. "Experenciar" esse episódio passado pela primeira vez no presente com o analista, seria o equivalente a levantar a repressão no paciente neurótico (Winnicott, 1954).

Em outras palavras, os sintomas que alguns pacientes nos apresentam são remanescentes e/ou consequências de um desastre e ocultam, mais do que revelam, o caminho ou as vias que o analista poderia seguir até a dor primordial. A experiência clínica continuamente nos apresenta evidências de algo remanescente de estados mentais que poderíamos localizar na pré-história de alguns pacientes adultos (Cassorla, 2008; Korbvicher, 2005; Sapienza, 2008).

Em situações clínicas semelhantes às abordadas aqui, Winnicott (1965) aponta o risco de nos tornarmos cegos para o eu primordial do paciente, se nos deixarmos enganar pela presença de um adulto articulado. Isso coincide com a observação de Bion (1975a) de que, em certas situações, olhar o paciente como 
adulto pode ser tão intrusivo que nos cega a sentimentos que não são evidentes para os sentidos.

Acredito que ambos, Winnicott e Bion, não se referem a uma estratégia técnica, mas à posição do psicanalista na sala de análise, no aqui e agora da sessão, ao estar com você mesmo para poder estar com o paciente. Sem memória ou desejo, abstraindo-se do discurso aparentemente lógico do paciente, levantar os limites da própria atividade racional do psicanalista. Como um marinheiro que atravessa tempestades precisa esquecer mapas e cartografia, o psicanalista deve poder perder-se, esquecer a categorização de pensamentos que pertence ao estado habitual de vigília; ser um ouvinte receptivo e continente, confiando mais na própria rêverie (devaneio), capacidade negativa e na possibilidade de movimentos $\mathrm{PS} \leftrightarrow \mathrm{D}$, do que na eventual atribuição de "conhecimento" e significados. Um analista presente de corpo e alma, capaz de transformar a ausência não representável em presença, de atravessar suas próprias fronteiras (cesuras) sem se assustar ou imobilizar, e transcender seus próprios vértices sem perdê-los de vista. Um processo sustentado no tempo pela presença do psicanalista em um ambiente capaz de proporcionar estabilidade, continuidade e autenticidade, condições fundamentais para a constituição de um sentido de si.

Outro capítulo da história seria o fomento das condições psíquicas a serem privilegiadas durante nosso processo de vir a ser, becoming, psicanalistas, o que nos possibilita desenvolver um estado mental de receptividade e atenção, com a possibilidade de viver uma "mente em trânsito" sem portos seguros para atracar. Como Bion pergunta em "Caesura" (1975a): "com que facilidade você pode mudar mentalmente sua posição, seu vértice, para poder quase ver os dois lados?”. Eu acredito que ele estivesse se referindo aos aspectos somato-psicóticos dos psicanalistas. Bion sugere que podemos compreender essas transformações da mesma maneira que fazemos, por exemplo, para compreender música, utilizando a disciplina e as regras, por assim dizer, que governam as alucinações. Esse seria o domínio ao qual pertencem as transformações de e em "O".

Com o conceito de uma mente multidimensional, torna-se necessário agora ao analista abrir caminhos e passagens, atravessar cesuras entre as diferentes dimensões psíquicas. Ou seja, penso que a função do analista envolve não apenas ideias em trânsito, mas um analista com uma mente trânsito, um "vir a ser" no sentido de poder transcender seus vértices (suas fronteiras), sem perdê-los de 
vista, "ver" ambos os lados dos inúmeros espelhos/cesuras com que, qual Alices, nos deparamos diariamente. Encontrar as sensações ou emoções que nunca atingiram a consciência e acompanhá-los na travessia de suas cesuras.

Como ilustração, pretendo abordar algumas experiências clínicas com pacientes que me chegaram apresentando um sofrimento psíquico peculiar, além de uma incapacidade de "sonhar", uma condição com frequência crescente em nossa prática atualmente.

\section{Referências}

Barros,E.R. (2000) Affect and pictographic image: the constitution of meaning in mental life. Int $J$ Psychoanal 81: 1087-99

Bion WR (1962) Learning from experience. London: Heinemann

Bion WR (1963) Elements of psycho-analysis. London:Heinemann

Bion, WR (1973-1978) Bion's Supervisions in Sao Paulo - from 1973 to 1978

Bion WR (1978) Four discussions with W.R.Bion \& Bion in New York and SaoPaulo. London: The Roland Harris Educational Trust 1978 \& 1980.

Bion WR (1992) Cogitations. London: Karnac Books.

Bion WR (1975a) "Caesura" in "Two Papers - The Grid and Caesura", p 56 London: Karnack Books (1989).

Bion, WR (1975b) "The Grid" in "Two Papers - The Grid and Caesura" London: Karnack Books (1989).

Cassorla RM (2008) The analyst's implicit alpha-function, trauma and enactment in the analysis of borderline patients. Int J Psychoanal 89 (1):161-180 Grotstein JS (2000) Who is the dreamer who dreams the dream? A study of psychic presences. Hillsdale: Analytic Press

Korbivcher, CF (2005) The theory of transformations and autistic states: autistic transformations: a proposal. Int. J. Psychoanal 86 (6): 1595-610.

Meltzer D (1979) Sulla bidimensionalità. Quaderni di Psicoterapia Infantile 3: 77-88, 1980.

Mion CC (2006) The Stranger Int J Psychoanal 87:125-43

Mion, C.C. (2019) Conjectures about dreams, memories and caesuras. In: Explorations in Bion's “O” - Everything We Know Nothing About. Ed. Afsaneh K. Alisobhani and Glenda Corstorphine. New York: Routledge. 
Ogden T (2004) This art of psychoanalysis: dreaming undreamt dreams and interrupted cries. Int. J Psychoanal 85:

Sapienza A (2008) "Alfa-Function: Catastrophic Anxiety - Panic - Continent with Reverie". Presented in Roma: Bion Conference 2008

Winnicott DW (1954) Metapsychological and clinical aspects of regression within the psychoanalytical set-up. In: Through Pediatrics to Psychoanalysis (pp 278294) London : Hogarth Press, 1987

Winnicott DW (1962) "The Aims of Psycho-Analytical Treatment". In: The Maturational Processes and the Facilitating Environment. Madison: International Universities Press

Winnicott DW, et all (1963) The fear of breakdown. In: Psycho-analytic Explorations p.81 Harvard University Press, 1989. 